\title{
A COMPARATIVE STUDY OF PLECOTUS AURITUS AND P. AUSTRIACUS (CHIROPTERA, VESPERTILIONIDAE) INHABITING ONE ROOST
}

\author{
by
}

\author{
R. E. STEBBINGS
}

Nature Conservancy, Coastal Ecology Research Station, Colney Lane, Norwich, Nor. 70F, Great Britain

\section{INTRODUCTION}

This study began in November, 1960 and involved studies of all bats living within one large and complex roof. Furzebrook House, built in 1885, was of brick with hollow walls and a black slate roof. The roof consisted of 9 distinct sections comprising some $385 \mathrm{~m}^{3}$ of which $60 \%$ was accessible for searching. Eight species were caught in these accessible regions and because Plecotus spp. were the most numerous, they became the chief study. The study became more significant when Plecotus austriacus (Fischer) (first described by Bauer, 1960), was identified in the roof. Detailed descriptions of the two English Plecotus have already been published (cf. Stebbings, 1967).

The aim of this report is to present evidence that might suggest reasons for the distribution of the two Plecotus in northern Europe, and particularly their northern limits.

\section{METHODS}

These have been described in detail in Stebbings (1966b). Environmental measurements and other results of this work appear in Stebbings (1966a) and (1966c). Essentially the study involved a standardised "search" which was evenly distributed throughout each year of the nine year period. Although both species were known to be in the roof throughout the year, during most searches no bats were caught.

\section{POPULATIONS}

Certain initial basic assumptions were made in these calculations. It was assumed that the colonies remained constant in respect of sex ratio, birthrate, age structure and death-rate (or at least emigration equalled immigration). Deviations from these will be reported below.
Plecotus auritus. - The calculated mean annual increment amounted to 5.012 bats $(\mathrm{p}<0.001)$ and the basic population calculated from a regression was 20.059 bats. Numbers actually known to be alive each year through recaptures were 17, $18,20,18,20,17,16$, and 17.

Survival rates were calculated from the fractions of recapture for males, females and combined sexes plotted as a function of time. Straight regression lines were calculated which closely $(<0.001$ in each case) fitted the available points, indicating a constant loss (death) rate. The survival rates were for males 0.542 , females 0.758 and sexes combined 0.743 . The life span can be calculated as the time elapsed from the initial banding of a population to the time when one per cent of the original total survived. With $P$. auritus it was 7 years for males, 16 years for females and 15 for sexes combined.

Since the increment rate and survival rate were shown to be constant the population number should also have remained constant and this was supported by the annual recaptures.

Plecotus austriacus. - The calculated mean increment amounted to 3.119 bats $(P<0.001)$ and the basic population figure calculated from a regression was 16.34 bats. However, this was slightly anomalous because by the end of the first year 22 had been caught and it was unlikely that this was the total. Thus, because the mean increment was only 3 bats per year, it would suggest that a change resulting in a reduction of the population occurred sometime after 1961.

During the first half of $1962,15 P$. austriacus were known (from recaptures) to be in the roof and there were probably a few others, but by the end of the year only 5 were known to be alive. In 1963 no new $P$. austriacus were found and only 4 bats banded prior to 1963 were recovered after 
that year. This large drop in numbers coincides with the severest winter (1962-3) known in southern England for over 100 years. Outside the roost temperatures were recorded down to $-17^{\circ} \mathrm{C}$ and the cold period lasted from late December until April. I believe that there was high mortality of $P$. austriacus due both to low temperatures in the roost and to the prolonged winter with resultant shortage of food in the spring. $P$. auritus prefers colder hibernating conditions (Harmata, 1969) and did not suffer any similar loss. In 1967 the number of $P$. austriacus was known to be at least 13 and appeared to be increasing. Annual numbers of bats known to be alive from 1961 were $16,15,5,8,6,8,13$ and 8 .

Survival rates for $P$. austriacus calculated from recapture fractions were obviously influenced by the 1962-63 winter. Straight regression lines were fitted to the plotted fractions of males (P.0.01$0.001)$, females and sexes combined $(P<0.001)$. Survival rates were for males, 0.452 , females 0.621 and sexes combined 0.523. Corresponding life spans would be 5, 9 and 7 years respectively.

These results indicate that females were found over a longer period of time and that the males were lost from the populations earlier than females. Whether this greater loss was a function of differential mortality, emigration, or avoidence of the observer was not determined, but the catchability (number of animals caught per unit search effort) declined at a constant 0.060 per year (P 0.01$0.001)$. In addition $P$. austriacus had a much lower survival rate than $\boldsymbol{P}$. auritus in this roost.

\section{RECAPTURE PATTERNS}

Bats were only caught on 360 of a total of 1092 searches, but during a further 84 searches over 400 active Plecotus were seen, but could not be caught. There were other searches when no bats were seen but squeaks and other noises indicated their whereabouts. Because of this close watch on the roost, confident statements regarding the populations were possible.

Different roof sections were used by each species at certain times of the year and were conveniently divided into hibernation, parturition and communal roosting sites.

The broad recapture patterns for each species and sex are summarised in table $I$.

It was evident that $P$. austriacus did not have such a high initial recovery rate as $\boldsymbol{P}$. auritus but was recaptured generally twice as frequently and mostly in intervals of 1 to 4 months. This was surprising because the parturition site for $P$. auritus was in the ridge tiles over the largest and most accessible communal roosting site while the $P$. austriacus parturition roost was a completely isolated and inaccessible roof section.

Although there were these large differences in frequency of recapture and recapture interval there was a high interspecific correlation concerning the initial recapture pattern. The proportion recaptured during the first month after banding was 0.302 and 0.372 for $P$. auritus and $P$. austriacus. The proportion recaptured one month after banding of those never recaptured again were 0.048 and 0.047 respectively and those recaptured one month after initial capture and subsequently recaptured were 0.254 and 0.233 . Thereafter the recapture pattern changes. Recaptures of individual $P$. auritus during two consecutive months with subsequent recaptures of greater than one month interval amounted to 0.224 (30 bats), while the corresponding figure for $P$. austriacus was 0.500 (39 bats), (significantly different $P 0.01-0.001$ ). Conversely $P$. auritus were recaptured more frequently with intervals of greater than one month and was significantly different from $P$. austriacus $(P<0.001)$. Thus there was the situation of $P$. austriacus being recaptured many times over a short length of time while $P$. auritus were recaptured a few times over a long period of time. This

Table I.

Number of bats handled and their recapture proportions.

Number of bats banded

Proportion recaptured at least once

Total bat/month recaptures

Proportion recaptures of 1 month interval

Proportion recaptures of 2 to 4 months interval

Proportion recaptures of 5 months interval and over

Mean number of bat recaptures of less than 1 month interval

\begin{tabular}{cc}
\multicolumn{2}{c}{ P.auritus } \\
$\delta \delta$ क & क $\%$ \\
27 & 36 \\
0.704 & 0.750 \\
67 & 121 \\
0.313 & 0.273 \\
0.283 & 0.206 \\
0.403 & 0.521 \\
3.21 & 2.52
\end{tabular}

\begin{tabular}{cc}
\multicolumn{2}{c}{ P.austriacus } \\
$\delta$ o & क $~$ \\
16 & 27 \\
0.687 & 0.593 \\
56 & 67 \\
0.482 & 0.443 \\
0.250 & 0.388 \\
0.268 & 0.179 \\
8.00 & 5.13
\end{tabular}


supports the disproportionate values for survival described above.

Further differences in recapture patterns involved changes in the mean recapture interval as the number of recaptures of each individual increased. Only inter-specific relationships need be discussed since no significant differences were found intra-specifically. The results were examined by calculating the mean recapture interval for every recapture, table II. Only the first six recaptures will be considered here due to the low numbers of individual bats recaught more often than this. of adult males from females and subadults occurred and the then pregnant females migrated to their respective parturition roosts where they remained throughout July and most of August. After mid-August juvenile and parous female $P$. auritus reappeared and a week later adult males returned.

During June, July and August the numbers of adult male $P$. austriacus increased to a peak at the beginning of September when they were joined by the post-weaning parous females. For this species copulation began in mid-September and continued for about a month. $P$. auritus began copulation again about the beginning of September and ap-

Table II

Mean recapture interval (months) per recapture number, per individual (1st, 2nd, 3rd recapture, etc.,)

Each recapture of less than one month was scored as one month Numbers in brackets $=\mathbf{n}$.

\begin{tabular}{|c|c|c|c|c|c|c|c|}
\hline Species & 1 & 2 & $\begin{array}{c}\text { Recapture } \\
\mathbf{3}\end{array}$ & $\begin{array}{c}\text { number } \\
4\end{array}$ & 5 & 6 & $\begin{array}{l}\text { Total period for first } \\
\text { recaptures (months) }\end{array}$ \\
\hline$P$. auritus & $\begin{array}{r}5.0 \\
(48)\end{array}$ & $\begin{array}{r}5.5 \\
(35)\end{array}$ & $\begin{array}{r}6.2 \\
(31)\end{array}$ & $\begin{array}{r}5.5 \\
(27)\end{array}$ & $\begin{array}{l}5.0 \\
(25)\end{array}$ & $\begin{array}{l}4.2 \\
(22)\end{array}$ & 31.4 \\
\hline P. austriacus & $\begin{array}{c}2.7 \\
(29)\end{array}$ & $\begin{array}{r}1.7 \\
(20)\end{array}$ & $\begin{array}{c}1.2 \\
(18)\end{array}$ & $\begin{array}{c}2.8 \\
(16)\end{array}$ & $\begin{array}{c}3.8 \\
(12)\end{array}$ & $\begin{array}{c}4.2 \\
(12)\end{array}$ & 16.4 \\
\hline
\end{tabular}

It was evident that the first 3 recaptures of $P$. auritus had an increasing period between them while the reverse was shown for $P$. austriacus. Thereafter the time intervals converged until the sixth recapture when both were refound with the same period of 4.2 months. From these results $P$. austriacus was more active in the roost and had a more cohesive colony than $P$. auritus, but it was also evident from additional observations that $P$. austriacus males were territorial in behaviour, but not male $P$. auritus.

\section{ACTIVITY CYCLES}

The lest active month for both species was February, with only very occasional arousals.

The bats were similarly inactive in March, with the exception of female $P$. austriacus, as they began to emerge from hibernation during the last week. By the first week of April all the $P$. austriacus females were active. Both sexes of $P$. auritus began their emergence together and by the middle of the month were in a very active state. $P$. auritus copulated during April and again in the autumn, but $P$. austriacus only copulated in the autumn.

Male $P$. austriacus did not hegin to emerge until the last week of April and they were not very active until the end of May. During June segregation peared to continue to the end of October, but conclusive evidence was lacking on this. It was probable that copulation continued throughout hibernation as in other Vespertilionidae but this was not observed (Strelkov, 1962).

$P$. austriacus females returned to hibernation in October and the males followed by mid-November. Male and female $P$. auritus were still active in the first half of November but by the end of the month all were hibernating.

During December $P$. austriacus females had a burst of activity which was associated with change of roosting site, but the males and $P$. auritus were inactive. $P$. auritus remained inactive during January but the male $P$. austriacus changed their roost during the first week and the females again during the last week.

\section{BODY WEIGHT CHANGES}

$P$. auritus were weighed on 293 occasions and $P$. austriacus on 299. The intraspecific weight cycles in males and females were generally similar (omitting pregnant females), although pre-hibernation weights of females were $1.0 \mathrm{~g}$ heavier than males and post-hibernation weight differential was $0.5 \mathrm{~g}$ in $P$. auritus and $0.8 \mathrm{~g}$ in $P$. austriacus. The only other important variation was that post-hiberna- 
tion weight increase began at the beginning of April for female $\boldsymbol{P}$. austriacus, while the males began in May.

In January $P$. auritus averaged $8.0 \mathrm{~g}$ and $P$. austriacus $10.0 \mathrm{~g}$. Both fell steadily until mid-April when they weighed $7.0 \mathrm{~g}$ and $8.0 \mathrm{~g}$ respectively. Thereafter their weights increased steadily and equally until the third week of August ( $8.8 \mathrm{~g}$ and $10.0 \mathrm{~g}$ ), when a sudden drop occurred of $0.6 \mathrm{~g}$ in $P$. auritus and $0.3 \mathrm{~g}$ in $P$. austriacus. Their weights remained at about $8.2 \mathrm{~g}$ and $9.7 \mathrm{~g}$ respectively until the end of September, when a rapid accumulation of fat took place. Within two weeks $P$. auritus gained $0.8 \mathrm{~g}$ and $P$. austriacus $1.6 \mathrm{~g}(9.0 \mathrm{~g}$ and $11.3 \mathrm{~g})$. The cause of the weight drop in September appeared to be an annual period of barometric depressions with warm, strong winds that prevented the bats from feeding.

The hibernation weight losses amount to $22 \%$ for $P$. auritus and $29 \%$ for $P$. austriacus.

\section{CONCLUSIONS}

$P$. auritus is common and widely distributed over the British Isles and almost the whole of Europe northwards to latitude $64^{\circ} \mathrm{N}$. P. austriacus has only been recorded from three English counties and south of $51^{\circ} \mathrm{N}$ latitude, while in Europe its distribution is more continental. It appears to be much less common, or absent from, north-western areas. The most northerly records were from Poland at a latitude of nearly $53^{\circ} \mathrm{N}$. (Ruprecht, 1965.)

Since the two species were found in the same roof, and by comparison of the known habits in Europe, it was possible to suggest reasons for the difference in their northern distribution. $P$. austriacus hibernated in warm regions (about $12^{\circ} \mathrm{C}$ ) while $P$. auritus preferred cooler conditions (about $6^{\circ} \mathrm{C}$ ). However, the hibernation localities in the roof where $P$. austriacus was found were subject to large fluctuations in temperature and this caused frequent arousals and consequent weight loss.
During the summer months the larger $P$. austriacus was not found in the high ambient temperature roof sections and did not form clusters, both of which the smaller $P$. auritus seek. The latter's parturition roost was in the highest south-east position of the roof and this was warmed by the first morning sun.

$P$. auritus was always placid when handled, but $P$. austriacus usually reacted vigorously and was often impossible to handle due to the possibility of damaging them. One female $P$. austriacus had to be killed because a humerus was broken during violent struggling. Both species were found with injuries such as torn skin and broken bones. $35 \%$ of $P$. austriacus were injured and $16 \%$ of $P$. auritus, but severe or fatal injuries amounted to $23 \%$ and $3 \%$ respectively. It was thought that many of these injuries were the result of intraspecific aggression since only one adult male $P$. austriacus per roof section was recorded at one time, while several (up to) 5 adult male $P$. auritus were frequently seen in clusters.

This apparent aggression and greater activity combined with the probable unsuitable hibernation conditions (indicated by winter activity and greater weight loss) and a too variable winter climate in southern England may account for the low survival rate for $P$. austriacus, while $P$. auritus appeared to be much better adapted to the environment. That $P$. austriacus survives in southern England may be due to relatively larger biomass of flying insects available during warm evenings in winter, whereas further north the supply may be insufficient. The critical factors in limiting the distribution of bats in temperate climates are not only the availability of suitable hibernation conditions, but more important, in my opinion, is the availability of food.

In conclusion $P$. auritus seems adapted to a temperate climate with variable climatic conditions at all times of the year while $P$. austriacus appears to favour the more stable continental environment.

\section{REFERENCES}

Bauer, K., 1960. Die Säugetiere des Neusiedlersee-Gebietes (Österreich). Bonn. zool. Beitr., 11 : 141-344.

Harmata, W., 1969. The thermopreferendum of some species of bats (Chiroptera). Acta Theriol., 14: 49_ 62.

RUPRECHT, A., 1965. Methody wyrózniania Plecotus austriacus. Fischer, 1829 i nowe stanowiska tego gatunku w Polsce. Acta theriol., 10 : 215-220.

Stebbings, R. E. 1966a. Bechstein's Bat Myotis bechsteini (Kuhl) in Dorset 1960-1965. J. Zool. London, $148: 574-576$.
,$- 1966 \mathrm{~b}$. A population study of bats of the genus Plecotus. J. zool. London, 150 : $53-75$.

-, 1966c. Bats associated with a Plecotus colony. J. zool. London, 150 : 492-493.

- , 1967. Identification and distribution of bats of the genus Plecotus in England. J. zool. London, 153 : $291-310$.

STrelkov, P., 1962. The peculiarities of reproduction in bats (Vespertilionidae) near the northern border of their distribution. Symp. theriol. Praha, 1962 : 306311. 